\title{
AFP Level Finding
}

National Cancer Institute

\section{Source}

National Cancer Institute. AFP Level Finding. NCI Thesaurus. Code C157163.

A finding that indicates the amount of alpha-fetoprotein tumor marker in a sample. 